\title{
LA GANADERÍA EN RAPA NUI, UNA VARIABLE ECONÓMICA POLÍTICA A CONSIDERAR
}

\author{
LIVESTOCK IN RAPANUI AN ECONOMIC VARIABLE POLICY TO CONSIDER
}

\author{
Rolf Foerster $^{1}$
}

\begin{abstract}
¿Es posible comprender la escena política rapanui sin considerar el papel de la ganadería? ¿Por qué el ganado puede circular libremente en la Isla y no así los humanos? ¿Qué valor simbólico y qué tipo de agencia hay en ellos? Estas son las preguntas que intentamos responder en este artículo y lo hacemos desde estas premisas (o hipótesis): la ganadería fue el gran motor de la economía insular desde fines del siglo XIX hasta la década 1960, en ese tiempo los rapanui estuvieron constreñidos a vivir en Hanga Roa; fue en ese espacio de dos mil hectáreas donde desplegaron su crianza de vacunos y equinos, en tanto en las "tierras fiscales" del Parque Nacional (14 mil hectáreas) se desarrolló la ganadería ovina en manos de una empresa privada, primeramente, y posteriormente de la Armada. En 1966 con la administración civil y con el desarrollo de la economía turística la ganadería rapanui entró en la disputa soberana sobre las "tierras fiscales" del Parque Nacional. En esa batalla el caballo jugó un rol central, por su "potencia... por ser superior a nosotros", ingresando hasta hoy día a la agencia de la sociedad isleña.

Palabras claves: Rapa Nui, ganadería, soberanía y política.
\end{abstract}

Is it possible to understand the Rapanui political scene without considering the role of cattle raising? Why can cattle circulate freely on the Island and not humans? What symbolic value and what kind of agency do they bear? These are the questions we try to answer in this article, and we do that from the following premises (or hypotheses): cattle raising was the main engine of the island economy from the late 19th century until the 1960s, when Rapanui people were constrained to live in Hanga Roa; it was in that space of two thousand hectares where they deployed their breeding of cattle and horses, while in the "fiscal lands" of the National Park (14 thousand hectares) sheep farming was initially developed by a private company, and later by the Navy. In 1966, under the civil administration and due to the development of the tourism, Rapanui cattle raising challenged the sovereignty over the "fiscal lands" of the National Park. In that dispute, the horse played a central role, because of its "power... for being superior to us", obtaining an important role in the agency of the society of the island until today.

Key words: Rapa Nui, livestock, sovereignty and politics.

Pero cuando vieron llegar a la playa una vaca y un caballo su asombro no tuvo límites (1866)1. Un día lo llevó a un potrero y le dijo: - ¿Ves esos caballos? Son míos. Ahora son tuyos. Elige los que quieras. O si quieres, te los regalo todos (Laferte 1957:215)².

Nos vemos obligados (subordinados) a la voluntad, o la potencia, del caballo para nuestro rápido traslado y para poder recorrer distancias grandes. Sin el caballo seríamos incapaces, impotentes de realizar tales acciones; de ahí, que la potencia, la capacidad, sea del caballo, no nuestra. El caballo es pues, superior a nosotros [...] De esta misma idea de superioridad del caballo, nace el sentimiento pascuense de no matar ningún caballo, ni consumir su carne (Fuentes 1960:55-56).

\footnotetext{
${ }_{1}^{1}$ Departamento de Antropología, Facultad de Ciencias Sociales,Universidad de Chile, Santiago,Chile. rolf22@gmail.com
} 
La colonización de Rapa Nui es inseparable del desarrollo de la ganadería. Hasta la década de 1970 la crianza y explotación de ovejas (mamóe), vacunos (pua'a), caballares (hoi) y cerdos (óru), fue el motor de la economía insular (la que era inseparable de la economía de "subsistencia" rapanui, que también desarrolló su propia ganadería). Desde mediados de la década de 1960 ese motor comenzó a ser sustituido por el de la industria del turismo, la que quedó en manos rapanui, del mismo modo que la ganadería a gran escala de caballares y vacunos en Hanga Roa y en el Parque Nacional.

La economía ganadera no solo requiere un "desierto biopolítico", sino también de una particular sensibilidad frente al patrimonio arqueológico: libre tránsito para los animales y quemas anuales de pastizales ${ }^{3}$. No sucede lo mismo con la industria turística, que promueve la restauración, conservación y exposición de los monumentos. En este contexto son pertinente las preguntas: ¿Por qué en Rapa Nui el ganado de la "comunidad" ha tenido, desde la década de 1960, una presencia masiva en el Parque Nacional, sabiendo los daños que producen a los monumentos? ¿Por qué pueden circular caballos y vacunos sin ningún tipo de restricciones? ¿Por qué se sanciona (2018) a una joven continental por subirse a un moai y besarlo y no se sanciona a los dueños de los animales que se suben a un ahu? ¿Qué hay en juego con dichos animales?

Hay consenso entre los investigadores que con la Ley Pascua (1966) se abrió un nuevo escenario político en Rapa Nui: la isla y sus habitantes ya no están bajo la tutela de la Armada, sino del Ministerio del Interior. Una de las consecuencias no esperadas de este cambio fue/es un conflicto territorial, en particular con el sistema parcelario ${ }^{5}$, una modalidad de propiedad por la cual los rapanui administraron y trabajaron sus economías campesinas: ¿en qué espacio había que instalar a las más de 20 instituciones de la administración civil?, ¿dónde vivirían los cientos de funcionarios continentales? La respuesta obvia fue en Hanga Roa, pero ese espacio estaba distribuido y apropiado por el sistema parcelario. En dicho sistema estaba además encapsulada la ganadería rapanui en un doble registro: los vacunos en las parcelas (su valor comercial era mayor: no solo se consumía su leche sino su carne), mientras los caballares gozaban de una mayor libertad pudiendo circular por Hanga Roa. Esa ganadería había estado en competencia con la que se desplegaba al interior del territorio controlado por la Compañía Explotadora de la Isla de Pascua (en adelante CEDIP) y posteriormente por la Armada, que ocupaba casi el $80 \%$ de las tierras, y cuyo rubro era la ovejería. Es sabido el colapso de esa industria ovejera en la década de 1970, lo que no se sabe son las transformaciones en la ganadería (bovinos y caballares), ahora en manos rapanui, y sus consecuencias económicas y políticas. Es lo que nos interesa explorar, sobre todo porque hace visible una agencia que permite ponderar de mejor forma no solo las transformaciones modernizadoras de los años 1960 sino también los actuales conflictos territoriales.

Por otra parte, hay cierto consenso que el origen del Consejo de Ancianos (1984) del Parlamento Rapanui y recientemente de los Hōnui, está ligado directamente al tema de las tierras (a su control y acceso) en cuyo valor hay que considerar a la ganadería. De forma más precisa: se debe tener en cuenta que la ganadería post1960 es ser un medio para un fin, y ese fin es la lucha de las familias por el control de las "tierras fiscales" (en Hanga Roa en primera instancia, en el Parque y en el Fundo Vaitea, en segunda), bajo el supuesto o la creencia de que el ganado crea las condiciones para el dominio. Nuestra impresión es que este proceso (de control) ya estaba presente, desde la década de los años 20, en las 2.000 hectáreas de Hanga Roa.

La hipótesis anterior obliga entonces a problematizar los cambios que se produjeron en la ganadería rapanui. Hasta mediado de la década de los años 60 la ganadería bovina y equina se desplegaba al interior de Hanga Roa (dentro y fuera del sistema parcelario), bajo la Ley Pascua (post-1960) y, con la creación del Parque Nacional y del Fundo Vaitea, se hará al interior del Parque. Este tránsito le permitió un desarrollo inaudito: 3.434 cabezas en 1966, 5.000 en $1971^{6}, 4.815$ en el 2007 y 6.221 en el $2011^{7}$. Ahora bien, este crecimiento llevó consigo la emergencia de una economía ganadera rapanui "comunitaria" que encubre a un grupo reducido de grandes propietarios de ganado (lo mismo sucede con la industria del turismo). Se trata, y esta es nuestra hipótesis central, de un empoderamiento que es visto como de la comunidad, no solo económico sino también político (Leviante Araki, presidente del Parlamento Rapanui, es también uno de los mayores propietarios de ganado; Matías Riroroko, presidente del Hōnui, es el mayor empresario turístico, con propiedades en la Isla y en el continente).

¿Lo anterior explica la "agencia animal"? Todos saben del daño que provocan los animales al patrimonio arqueológico, no obstante nada significativo se hace para impedirlo. ¿Cómo entender esta situación? Si vamos a la literatura clásica (McCall 1976, 1998; Cristino et al. 1984; Delsing 2017; Porteous 1981) no hay respuesta, hay que ir a un artículo de José Miguel Ramírez (2004) para encontrar una primera explicación: "el ganado no tiene un sentido económico sino político en la ocupación del territorio" (Ramírez (2004:496). Llamó al fenómeno la "vaca sagrada", pero en sentido estricto debería ser, como veremos, el "caballo sagrado". Agréguese la tradición alimentaria: en 1965 el consumo anual de carne era 150 kilos, cuando el promedio nacional era de 32 a 
$55 \mathrm{kilos}^{8}$. Este "exceso" también tiene una cara política: en 1954 los representantes rapanui -Pedro Atán, Lázaro Hotus, Alberto Hucke y Juan Pont- le solicitaron a las autoridades "que no venga más gente del Continente a establecerse a la Isla, porque mayor número de personas dificulta el abastecimiento de carne. Si llegan más continentales disminuye la carne que necesitan las familias". Pensamos que este es el punto de partida para dar una nueva lectura del pasado ganadero y de lo que está en juego en el presente.

La investigación sobre la ganadería es reciente y muy reducida, el trabajo más relevante, por la sistematicidad de la información, es el de la Consultora MOBA del año 2011. Con este trabajo al fin tenemos datos sobre los "ganaderos", su desempeño y cantidades de animales que controlan, las tierras que ocupan, etc. La tesis de la ingeniera forestal Janneke A. Gisolf, del año 2002, titulada "La ganadería Rapa Nui. El inicio a la participación", tiene el mérito de ser la primera entrar al asunto desde una perspectiva etnográfica, permitiéndonos conocer las valoraciones sobre el ganado que hacen los habitantes de la Isla: ya sea como inversión, para la seguridad alimentaria, para la distinción social y económica, pero también, como medida de "presión para obtener tierra" (Gisolf 2002:29).

Por nuestra parte, para la reconstrucción histórica de la ganadería hemos usado los informes de la Armada ${ }^{10}, \mathrm{y}$ para la actual problematización los archivos judiciales y la emergencia de la cultura yorgo (un grupo de jóvenes que en los 90 optó por irse a vivir al Parque y hacer una vida diferente a la que se desarrollaba en Hanga Roa). Desde esos lugares nos permitimos avanzar en nuevas preguntas.

\section{La Ganadería y su Dimensión Política en el Periodo de la Compañía (1895-1952)}

"Viven en cuarenta chozas... Cultivan con plátanos, camotes y otros tubérculos indígenas, algunas pequeñas extensiones... Los hombres son muy aficionados al caballo...” (Edwards 1918:20, 21 y 22). “...predomina en ellos la vanidad de sentirse propietarios de muchos animales" (Aceituno 1950).

La ganadería ovina (para la producción de lana fina), fue la clave de la CEDIP. Su desarrollo estuvo limitado tanto por la extensión territorial (las 16 mil hectáreas de la isla), como por las restricciones de la agencia rapanui que logró controlar un espacio propio: Hanga Roa (dos mil hectáreas). El mayor número de ovejas fue de 56.000 en el año $1940^{11}$, y de 5.000 vacunos y 1.000 caballares en 1923. Así la riqueza en Pascua se medía por animales.

Debe tenerse en cuenta que para los rapanui los animales de la Compañía no eran de su exclusiva propiedad, existía la creencia y el sentimiento que también les pertenecían a ellos, y esto por tres razones: la primera, que provenían de una donación a la comunidad realizada en el pasado por la Iglesia (con sede en Tahiti); la segunda, que sus animales les fueron arrebatados cuando fueron localizados en Hanga Roa; y, la tercera, los animales se alimentaban en las tierras rapanui (este conjunto de razones se encuentran en la rebelión de Angata de 1914). Otra dimensión a considerar era el "robo de corderos" (toque mamoe), que revela muchas cuestiones, no solo sobre la propiedad sino también de una suerte de pacto entre Comunidad, Compañía y autoridades chilenas (Métraux 1950).

La cara política sobre el ganado también estaba presente en el triángulo Comunidad, Estado y Compañía. Recordemos que en el Temperamento Provisorio de 1917, en su punto 5, se especificaba un traspaso de ganado de la Compañía a la comunidad:

Del ganado fiscal entregará la Compañía a
la custodia del Subdelegado diez yuntas de
bueyes, diez novillos y 60 vacas lecheras,
que se cargarán a la masa del ganado del
Gobierno y que recibirá el Subdelegado
bajo recibo. También podrá el Subdelegado
pedir a la Compañía hasta 50 lanares por
mes, que destinará a la alimentación de los
trabajadores que no sean de la Compañía...
Estos lanares no serán a cargo a la masa
del ganado fiscal, y es la participación que
corresponderá al Fisco en la producción
de su ganado.

La comunidad siempre estuvo atenta y vigilante de esta obligación mensual y anual de la Compañía. Posteriormente, en 1925, a través de una serie de diligencias los rapanui lograron destituir de su cargo al subdelegado Exequiel Acuña y también consiguieron una cuestión no menor y relevante para sus "economías campesinas": el traspaso de 500 vacunos que estaban en manos de la CEDIP:

... arreglo con los concesionarios, S.S. Williamson y Co., para que éstos entreguen a los Naturales para su usufructo i en forma de donación, hasta quinientos animales vacunos, en su mayoría vacas, para que cada familia pueda tener leche i queso en abundancia i beneficie las crías para su alimentación $^{12}$.

Lo anterior, que comenzará aplicarse en el año 1926, nos permite pasar al ganado rapanui.

Los rapanui mantuvieron post "acuerdo de voluntades" (1888) su economía de subsistencia, pero con la instalación de la Compañía (1895) y de la CEDIP (1903), que implicó la expoliación de sus tierras y ganado y su transformación en "colonos"(reducidos a Hanga Roa), su economía se "acopló asimétricamente" a ella, no solo aportando mano de obra (ya sea de forma permanente como también 
estacional, para la esquila y la carga y descarga de los buques), sino también produciendo para ella maíz en las parcelas propias (para la crianza de cerdos). Estaban excluidos de tener corderos (lo obtenían a través del toque mamoe), no así vacunos y caballares. Esto dio pie a una cuestión capital: el ganado no solo sería fundamental para las economías familiares, sino también una señal para la distinción interna.

Esta producción agrícola hecha en las parcelas (de los rapanui) requería el uso de tracción animal y no fueron los caballos sino los bueyes los utilizados. Estos serán "prestados" por la Compañía (no sabemos si se debía pagar por ello), y es el subdelegado marítimo, quien hacía de mediador en esta relación. Que los rapanui no tuvieran bueyes con anterioridad se explica porque para sus cultivos tradicionales no los requerían. No obstante, tenían caballos y vacunos, los que según el rodeo realizado por la comisión de von Schroeders en 1930, eran abundantes (500 caballares y 300 vacunos) más que los que tenía el fisco, y ocupaban parte de las 2.000 hectáreas "fiscales". ${ }^{13}$ Parte de los vacunos en manos de los rapanui provenían de la Compañía gracias a una política de donación y de intercambio por caballos, que como señalamos más arriba comenzó aplicarse con la llegada del subdelegado marítimo Carlos Recabarren en $1926^{14}$. En su Memoria de 1928 señala los efectos de esta campaña de donación y de sustitución de sus caballos por vacunos: "La Cía. Explotadora Isla de Pascua, ha seguido cambiando animales vacunos por animales caballunos en ésta temporada a cambiado cien animales. La gente ha quedado conforme con estos cambios" ${ }^{15}$.

Esta fascinación por el caballo se explica no solo por ser un medio de trabajo y transporte (y de estatus) sino también por una dimensión festiva: las carreras de caballo. Recordemos que entre las obras emprendidas por Bienvenido de Estella en 1918, se consigna una cancha: "A orillas del mar, junto a la playa de Hangaroa, tracé y formé una cancha de 350 metros de largo por 40 de ancho, para que los pascuense tuvieran donde hacer sus carreras de caballos y otros juegos: la inauguramos el 18 de septiembre fiesta nacional de Chile" (1921:12). Dos décadas después, en 1939, el Comandante Streeter, vuelve al tema: "Los Domingos en las tardes tienen carreras de caballos [...] lo que despierta en ellos el mayor entusiasmo"16.

\section{Los animales por sobre el sistema parcelario (pero al interior de Hanga Roa)}

Volviendo al punto 2 de la observación de Edgardo von Schroeders: "Los nativos tienen grandes cantidades de ganado vacuno y caballar que consumen casi la totalidad del pasto de los potreros fiscales" ${ }^{\prime 17}$. Se trata de nada menos que de 800 animales, 500 caballos y 300 vacunos. Téngase presente que a esa fecha había 363 personas ${ }^{18}$. Lo interesante de la observación del comandante de la Baquedano es que ese ganado está confundido con el fiscal y ocupan los "potreros fiscales", es decir, las tierras más allá de las parceladas. En otras palabras: los rapanui controlan las tierras parcelarias y a la vez, gracias al ganado, las tierras fiscales de Hanga Roa. Esta exclusión de los animales de las tierras cultivadas era una realidad a fines de la década de 1930 (Streeter Vicuña 1939:6). Y también a esa fecha el número de animales había aumentado a 1.300 (600 caballares y 700 vacunos), en tanto los fiscales estaban reducidos a 187 ( 7 caballares y 180 vacunos). El informe del veterinario Aurelio Ferrari de 1939, sobre los animales en manos rapanui y del fisco, era lapidario:

...son mestizos de heterogénea ascendencia
y de pequeña alzada, en los cuales se
advierte, a primera vista su degeneración.
Esto se debe al exceso de consanguineidad,
falta de selección y a una insuficiente
alimentación por abundancia de animales
en un terreno reducido. Estos, se reproducen
natural y libremente pastando en completa
promiscuidad. Por estas causas, el
rendimiento de una vaca lechera no alcanza
a 2 litros diarios. Igual cosa acontece con
los caballares, los cuales son pequeños, de
esqueleto reducido y degenerados ${ }^{19}$.

Esta situación contrastaba con los animales de la Compañía: "La sanidad del ganado es óptima" y su producción, más que satisfactoria: "La lana producida por los ovinos [...] es de excelente calidad [...] obtenida por una cuidadosa selección de los reproductores y dirigida por un personal técnico especializado, tiene un mercado seguro en el país y en el extranjero por varias condiciones: finura, resistencia y limpieza" (Ferrari 1939:3).

¿Jugó en esta situación una política de la Compañía? ¿Por qué los caballares y los vacunos de la Compañía no se cruzaban con los de los rapanui y del fisco? Tres años más tarde (1941) el número de animales en manos rapanui y del fisco era de 1.800 . No obstante, sus condiciones no habían mejorado, de allí la necesidad de intervenir en sus cruzamientos $^{20}$.

De este modo, el ganado en manos rapanui en una década había aumentado en un 100\%, de 800 a 1.646, una realidad sólo posible en los "potreros fiscales", aunque a ojos de un veterinario ese crecimiento daba como resultado animales de "ínfima calidad".

En el censo agropecuario de agosto de 1945 realizado por el Jefe Militar de la Isla, Ricardo Kompatzki, se puede observar un leve aumento del ganado rapanui (a 1.975 animales), con un dato clave hay 151 propietarios en una población de 578 habitantes ${ }^{21}$.

En el rodeo del 10 de junio de 1950 la cifra se mantuvo (1.273 vacunos y 511 caballares) y, según el informe del Jefe Militar, Luis Aceituno, se había llegado a un límite, ya no había más espacio útil para 
la ganadería rapanui en Hanga Roa. Los casi 1.900 animales era una "cantidad superior a las posibilidades de los campos que disponen los nativos para el pastoreo; de aquí es que el ganado sea de ínfima calidad"22.

¿Qué cambios se produjeron post 1954, cuando se puso fin a la CEDIP y la Armada se hizo cargo del "Fundo Rapa Nui"? Da la impresión de que la situación ganadera rapanui se mantuvo, no así en el "fundo", allí se comenzó a implementar el "Campo experimental Vaitea", con vistas a diversificar la producción agrícola ${ }^{23}$, como también un ambicioso proyecto de reforestación ${ }^{24}$. Lamentablemente no contamos con trabajos que den cuenta de la situación ganadera para los años 1955-1959. Para 1960 existe el "Informe sobre las posibilidades de fomento agrícola y pastoril en la Isla de Pascua", realizado por Arthur H. Delley, Asesor en Administración Ganadera y Producción de Pastos, Misión de Asistencia Técnica, FAO de las Naciones Unidas. Los antecedentes que aporta sobre la decadencia de la ganadería ("el número de animales y producción de la lana, han ido disminuyendo constantemente,") y las recomendaciones que propone (producción porcina, de maíz y cultivo de frutas), ponen en evidencia que la ganadería ya no era una opción económica para la Isla. Este es punto relevante: ¿la salida del ganado del "fundo", por disminución, daba pie para la entrada del rapanui?.

Para el año 1965, gracias al censo agropecuario, tenemos una visión precisa de la ganadería: "La población ganadera de la Isla está compuesta principalmente por ovinos alcanzando sobre las 30 mil cabezas, que maneja y cría exclusivamente el fundo fiscal Isla de Pascua; de este modo no les está permitido a los pascuenses poseerlos. En menos cantidad se encuentran los bovinos, caballares y porcinos, que se mantienen en libre pastoreo [...] Todas las tierras de la Isla son de propiedad fiscal, ocupando el fundo Isla de Pascua la mayor parte de ellas y donde se explota la ovejería. Los pequeños productores ocupan actualmente alrededor de $700 \mathrm{ha}$, cuyas parcelas pueden subdividir como les agrade entre parientes y amigos. La denominada Reserva Fiscal, aproximadamente 2.500 ha, está destinada a suministrar terrenos y campos de pastoreo a las nuevas familias que se formen entre isleños" 25 .

¿Pero cuántos animales estaban en manos rapanui en Hanga Roa, según este Censo? La cifra era de 1.565 , con un total de 825 vacunos (211 bueyes, toros y novillos; 390 vacas y vaquillas; 224 terneros) y de 740 caballares (163 porcinos y 2.034 aves). Posiblemente la cifra esté algo subestimada. La virtud de este censo es que nos permite tener una visión sobre la apropiación.

\section{La Revolución 1966, y la Ganadería en los Tres Espacios: Parque Nacional, Fundo Vaitea y Hanga Roa}

Ya que nosotros no podemos ocupar nuestro territorio libremente, que es nuestro, que nos corresponde, que nuestros animales entonces anden libremente. Ahí se tomó la decisión, los patriarcas y matriarcas, en un acuerdo secreto, decirle a nuestro hijos, a nuestros sobrinos, suelten los animales en el Parque (Petero Edmunds, en documental "Yorgos", de Paco Toledo y José Domingo Rivera, 2014.

Esta es toma, porque dicen que es Parque Nacional, ¿Quién es Parque Nacional? CONAF ¿Quién es CONAF? ¿Quién nos paga a nosotros por estar aquí? ¿Qué nos aporta? Nadie me hecha de aquí (Mario Olivares Paté, en documental "Yorgos", de Paco Toledo y José Domingo Rivera, 2014).

$\mathrm{Al}$ mes siguiente de haberse promulgado la Ley Pascua $\left(\mathrm{N}^{\circ} 16.441\right)$ se creó el Parque Nacional de Turismo de Isla de Pascua, con una superficie de 6.977 hectáreas, las que serán reducidas ese mismo año a 4.665. Con ello el "Fundo Isla de Pascua" devino, por un lado, en el Parque, y por otro, en el "Fundo Vaitea" (con 10 mil hectáreas). Vaitea será administrado por la Corfo (desde 1980 por SASIPA, una "filial" ad hoc de la Corfo) y sus funciones principales serán el "desarrollo y mejoramiento de la ganadería mayor y menor, empastadas, forestación, control de erosión saneamiento de pestes e introducción de frutales y de cultivos adecuados al clima de la región, todo ello en conformidad al espíritu de la Ley $\mathrm{N}^{\mathrm{0}} 16.441^{{ }^{\prime 226}}$.

En este nuevo marco, al quedar liberado de la carga animal del Fundo Vaitea, el Parque pasó a ser ocupado por la ganadería rapanui. Con ello el crecimiento fue espectacular, pero no de los bovinos sino de los caballares, como se señala en 1971:

\section{...los 825 caballares del censo en 1965, han aumentado a 5 mil cabezas contabilizados en octubre de 1971. Este incremento se debe a que no se consume carne de equino y también a la falta de control sobre la reproducción. Esta masa animal sólo presta servicios como medio de transporte y una ínfima parte es sacrificada para alimentar cerdos, constituye un elemento dañino para los suelos, la agricultura y los restos arqueológicos (Odeplan 1971:146-147, el destacado es mío).}

¿Cómo es posible que durante el periodo de la Unidad Popular, un organismo encargado de la planificación como ODEPLAN, no contemplara ninguna medida para frenar o mitigar ese "elemento dañino", a no ser de ciertos resguardos a los monumentos? $?^{27} \mathrm{Y}$ también, por qué no da cuenta que ese aumento de los caballares solo es posible al interior del Parque. ¿Hay que buscar 
la respuesta en el "pacto secreto entre patriarcas y matriarcas" señalado por el alcalde Petero Edmunds?

En esta pasividad del aparato del Estado, no deja de ser significativo que en la época de las cooperativas (19671976), impulsadas por los gobiernos de Frei y Allende, el tema de la ganadería nunca fue considerado como una actividad a controlar y planificar. Las dos mayores cooperativas, la Multi-Activa Rapa Nui ${ }^{28}$ y la Te Pito Te Henu $^{29}$, tuvieron como centro los temas agrícolas y de pesca. Nunca, en las pocas actas que conocemos, aparece formulada la idea de buscar un manejo del ganado bajo este tipo de cooperación. Por otro lado, la presencia de dos cooperativas enfrentadas, refleja la "división" de la comunidad, y esa "separación" posiblemente hacía difícil el manejo de un bien que ocupaba un espacio no "dividido" (y en pugna con los continentales chilenos, los tire).

En los primeros años de la dictadura (1973-1989) ODEPLAN impulsó un enorme programa de inversiones en infraestructura, pero no dispuso recursos destinados a la ganadería rapanui, pero sí a la fiscal en Vaitea (que es el proyecto con mayores fondos). Los recursos estaban destinados a procurar el autoabastecimiento de la Isla en materia alimenticia ${ }^{30}$.

Para la década de 1980 es muy escasa la información sobre la ganadería rapanui que se encuentra en los archivos del Estado pertinentes para la Isla (ODEPLAN, Intendencia de Valparaíso y Gobernación de Isla de Pascua). Distinta es la situación para el ganado fiscal localizado el Fundo Vaitea (que no logró nunca la meta de 3.000 vientres y la mentada política del autoabastecimiento fue un fracaso).

Para la decáda de 1990 de los 2.154 bovinos, 590 estarían en manos de "diversos particulares", es decir, de rapanui. No hay referencia a "miles" de caballares en el Parque. Para el año 1997, en base al censo agropecuario, solo tenemos cifras generales: 2.576 vacunos y 622 caballares. Diez años más tarde (2007) los números nuevamente son generales: 2.284 bovinos y 604 caballares. Está claro que los censistas no entraron al Parque.

El tema de la doble ganadería aparece con cifras desagregadas solo en la década pasada. En el estudio AMBAR del año 2001, destinado a determinar la capacidad de carga del territorio, se precisa que del total de animales 1.600 vacunos están en manos rapanui y 1.043 de SASIPA. La información le fue proporcionada a la Consultora por el gerente de Sasipa, Gerardo Velasco. Y nuevamente nada sobre los caballares en el Parque.

Diez años más tarde (2011) se cuenta con el trabajo de la Consultora MOBA, "Diagnóstico técnico y social de las prácticas ganaderas". Este estudio nos parece fundamental, sobre todo porque participaron los ganaderos rapanui entregando por primera vez información sobre sus prácticas y creencias. Su importancia radica en que entrega cifras para la ganadería rapanui y del control que tiene del Parque (PNRN):
Respecto al proceso productivo, se estableció que la cantidad total de cabezas de ganado asciende a 6.221, de las cuales 3.860 son bovinos (62\%) y 2.361 son equinos (38\%). Se realiza una producción de tipo extensiva (100\%) y un $79 \%$ de la alimentación es a base de pradera natural sin mejoramiento [...] Respecto al territorio utilizado por el ganado, se estimó que el 69,5\% de Isla de Pascua, correspondientes a 11.390 hectáreas, y el 80\% del PNRN, con 5.748 hectáreas, están siendo usados actualmente para el tránsito y/o pastoreo animal [...] este tránsito animal se halla en los sectores de mayor densidad arqueológica del PNRN, e invade el $67 \%$ de la superficie del PNRN que presenta densidades arqueológicas media a alta. El tránsito se está desarrollado en los sectores que ya cuentan con importante de erosión [sic], es así como el 65,4\% de la superficie de la Isla, en donde transitan los animales, presenta grados de erosión o deterioro del suelo y el $73 \%$ del espacio en que se desarrolla la ganadería en el PNRN presenta algún grado de erosión. La escasa flora nativa se encuentra en riesgo, ya que un $80 \%$ se halla en los sectores de tránsito y al alcance de los animales (MOBA 2011:910. El destacado es mío).

Esta masa animal de 6.221 (5.448 en manos rapanui y 773 en el fisco) es enorme para la Isla, si se tiene en cuenta el estudio de la consultora AMBAR que determinó que la "capacidad de carga animal máxima ideal, considerando entre otras variables la disponibilidad de forraje anual que necesita un animal para su alimentación adecuada, es de 2.249 cabezas de ganado" 31 .

Pero este estudio no solo tiene la virtud de darnos las cifras totales de ganadería, sino también de quiénes son los ganaderos: “...en el ámbito social y económico, se determinó que existen 40 ganaderos establecidos, 28 ganaderos asociados y se estableció además la existencia de la empresa SASIPA, que tiene el control del 13\% del total de las cabezas de ganado" (MOBA 2011:9).

El dato es muy fuerte (e inesperado), por un lado, el número de animales es el doble a la década anterior, donde el $87 \%$ del ganado está en manos rapanui, ocupando no solo las "antiguas" tierras de Hanga Roa, sino que el 80\% de las tierras del Parque Nacional. Los nombres de los propietarios y el número de animales que tienen (MOBA 2011:9):

\begin{tabular}{lc}
\hline \multicolumn{1}{c|}{ Nombre del Ganadero } & $\mathrm{N}^{\circ}$ de Animales \\
\hline Pequeño & \\
\hline 1. Manuel HEREVERI HEREVERI & 7 \\
\hline 2. Mihaera HAOA PAKOMIO & 8 \\
\hline 3. Omar CASTILLO & 8 \\
\hline
\end{tabular}




\begin{tabular}{ll}
\hline 4. Ricardo TEPIHE HOTUS & 17 \\
\hline 5. José PATE TUKI & 19 \\
\hline 6. Lidia PAMELA HUCKE HUCKE & 29 \\
\hline Mediano & \\
\hline 1. Jaime RIROROKO LAHAROA & 22 \\
\hline 2. Juan Alberto NAHOE HEREVERI & 23 \\
\hline 3. Pedro Vicente PONT PATE & 25 \\
\hline 4. Rodrigo Cipriano PAKARATI ARAKI & 25 \\
\hline 5. Ricardo Alejandro TEPIHE PONT & 26 \\
\hline 6. Ernesto VÁSQUEZ RIROROKO & 29 \\
\hline 7. Leandro ROBERTO HAOA PAKOMIO & 29 \\
\hline 8. Mihaera Peata PONT LILLO & 30 \\
\hline 9. David Mauricio PATE LILLO & 39 \\
\hline 10. Miguel HEREVERI ROJAS & 57 \\
\hline
\end{tabular}

y muchos explican la imposibilidad de cambiar el statu quo ganadero a su influencia (la actual administración del Parque, la comunidad Mau Henua, para evitar conflictos los incorporó a la planta de trabajo y de la administración).

La distribución desigual también pone en cuestión la tabla 17 del estudio MOBA (2011:70), que da cuenta de las "motivaciones para desarrollar la práctica ganadera" (2011:70):

1. Sustento Económico Familiar (Actividad Principal)

2. Generar Ingreso Secundario (Complementa el ingreso existente)

3. Salvavidas Económico (Venta en caso de Necesidad)

4. Autoconsumo (Productos Derivados y Economía Familiar)

5. Beneficiar con Carne a la Comunidad y a los Turistas (Productos Derivados)

11. Roberto Nicolás RIROROKO HEREVERI 58

\begin{tabular}{|c|c|c|}
\hline 12. José Jerónimo NAHOE PATE & 65 & \\
\hline 13. Rafael HEREVERI PAKARATI & 67 & \\
\hline 14. Ernesto Pablo TEPANO RAPU & 73 & \\
\hline 15. Nelson HEREVERI ROJAS & 81 & \\
\hline 16. Querubín CASTILLO VENEGAS & 82 & \\
\hline 17. Marcelo PONT LILLO & 90 & \\
\hline 18.- Emilio ARAKI TEPANO & 97 & \\
\hline 19.- Marco Antonio ARAKI VIZCARRA & 110 & \\
\hline 20.- José Miguel LEÓN IKA & 150 & \\
\hline 21.- Carlos EDMUNDS PAOA & 151 & \\
\hline 22.- Alejandro RAPU & 166 & \\
\hline 23.- Luis Miguel AVAKA TEAO & 175 & 1.670 \\
\hline \multicolumn{3}{|l|}{ Gran } \\
\hline 1.- Luis Enrique PATE TUKI & 204 & \\
\hline 2.- Julio OLIVARES PATE ${ }^{32}$ & 210 & \\
\hline 3.- Leviante ARAKI & 211 & \\
\hline 4.- Ruperto Samuel TEPANO TEAO & 227 & \\
\hline 5.- Pedro Antonio TUKI TEAO & 300 & \\
\hline 6.- Francisco José Ngara IKA PIZARRO & 324 & \\
\hline 7.- Marco Antonio OLIVARES PATE & 400 & \\
\hline 8.- Mario Esteban OLIVARES & 400 & \\
\hline 9.- José Guillermo PONT IKA & 420 & \\
\hline 10.- Pastor TUKI & 428 & \\
\hline 11.- Alberto Alejo ARAKI TEPANO & 565 & 3.689 \\
\hline SASIPA & 738 & \\
\hline
\end{tabular}

6. Beneficiar a la Comunidad en Curantos (Ayuda Social)

7. Beneficiar a los Turistas en Cabalgatas

8. Placer Personal

9. Por tratarse de una Herencia Familiar

10. Practica Natural

11. Medio de Transporte

12. Usar la Tierra

Ninguna de estas motivaciones puede explicar por qué una persona o una familia tengan varias centenas de animales (a no ser las categorías 8 o 9). Las razones que le dieron a Janneke Gisolf en 2001 nos parecen más relevantes: prestigio y control territorial, y son las que retoma José Miguel Ramírez bajo la imagen de la "vaca sagrada".

\section{Vaca (puáka) Sagrada-Caballo (hói) Sagrado}

...Tantas obras que se pudieron realizar gracias a tu visión aguda y sabia como líder... El Banco Ganadero que tu tan inteligente planteaste como una forma de forzar las primeras desafectaciones de terreno y así iniciar la recuperación en los siguientes años de las tierras ancestrales... (Carta de Francisco Valiente aAlberto Hotus, presidente del Consejo de Ancianos, 24/12/2016) ${ }^{33}$.

El arqueólogo José Miguel Ramírez fue, entre los años 1993 y 1999, Jefe Provincial de CONAF en Isla de Pascua y Administrador del Parque, de allí que su observación sobre la dimensión política del ganado tenga un sustento real: las controversias en que se vio envuelto con el poder local (Consejo de Ancianos $1^{\circ}$ y $2^{\circ}$, y con el abogado y Gobernador Jacobo Hey Paoa), al defender el patrimonio territorial y arqueológico del Parque Nacional.

Una de estas controversias la tuvo con Alberto Hotus, presidente del Consejo de Ancianos ( $\left.\mathrm{N}^{\circ} 1\right)$. En 1992 Hotus solicitó a CONAF el uso de 900 hectáreas en el sector La Pérouse del Parque para el proyecto 
"Banco Ganadero", financiado por la $\mathrm{OCAC}^{34}$. Se inició en 1992 con 72 vaquillas, tres años más tarde el plantel había aumentado a 240 animales. Lo novedoso de esta iniciativa radicaba en la búsqueda de un uso comunitario de las tierras y de la factibilidad de tener una ganadería que beneficiara a todos sus integrantes ("la comunidad"). Cuando asumió José Miguel Ramírez la dirección de CONAF de la Isla (1993) puso en cuestión la pertinencia de este proyecto, por no sujetarse a la reglamentación del uso de Parque. En una carta fechada del 2 de enero de 1995, enviada al Director Ejecutivo de CONAF, le señalaba:

...En la práctica, el Consejo de Ancianos considera esos terrenos como propios [...] En el hecho, el Consejo de Ancianos de Hotus no representa a la comunidad, existiendo otros particulares y grupos con los mismos intereses respecto de las tierras, tanto para el uso ganadero como de dominio. Se ha planteado la posibilidad de un convenio similar, a partir de una solicitud formal de un grupo encabezado por Don Emilio Araki, lo que ha sido evaluado positivamente en principio, a partir de la visita de profesionales de la oficina central ${ }^{35}$.

Lo que nos interesa destacar aquí es la pugna abierta en el seno de los ganaderos por el control territorial del Parque y cómo CONAF intervenía en estos asuntos favoreciendo a unos en desmedro de otros. Así en agosto de ese mismo año Ramírez puntualiza la opción que tenía el Consejo de Ancianos en un oficio al Gerente Técnico de CONAF:

...Como es de su conocimiento, en el último tiempo se ha tratado de regularizar el préstamo temporal y gratuito de terrenos del P.N. Rapa Nui para el talajeo de animales de particulares [...] el Sr. Hotus se opone que Conaf establezca convenios con otros particulares. Dijo que solicitó las tierras a Conaf a nombre de la Comunidad, y que él no quiere firmar un convenio como particular. En la práctica, esas 900 há del Parque no da cabida a todos los animales, ni siquiera para el Banco Ganadero del Consejo de Ancianos con apoyo técnico de la OCAC, puesto que suelen pastar a lo largo de la costa... Además el grupo que representa el señor Hotus no incluye a todos los isleños [...]...Si bien existe el riesgo cierto de que una ocupación temporal pueda convertirse en definitiva, aunque el convenio establezca que esto es mientras se ubiquen terrenos apropiados fuera del Parque, la única garantía para Conaf es un convenio ${ }^{36}$.
Ramírez estaba en un dilema: si optaba por el Consejo dejaba afuera a un grupo de "particulares", cuyos animales sumaban unos 1.400 vacunos y caballares, los que se encontraban mayoritariamente dentro del Parque. A ese fecha el Consejo de Ancianos estaba siendo impugnado por el Consejo de Ancianos $\mathrm{N}^{\mathrm{o}} 2$ (lo que nos recuerda la antigua división entre las dos cooperativas). Éste envió el 6 de noviembre de 1995 una misiva a Ramírez señalándole que:

Es inconcebible que el Sr. Hotus siendo miembro de la Directiva de SASIPA, sociedad que posee la mayoría de las áreas de pastoreo de la Isla, esté pretendiendo en nombre de la comunidad obtener terreno protegido por Conaf, en vez de preocuparse de ceder todas aquellas áreas de SASIPA, que no la usan, para talaje de animales de la comunidad ${ }^{37}$.

El escenario se complejizó al formarse una suerte de pacto entre CONAF y el Consejo de Ancianos $N^{\circ} 2$ contra el Fundo Vaitea (SASIPA), respecto de que éste tuviera las mejores tierras para el pastoreo, además con una menor densidad de sitios arqueológicos: “...sin perjuicio de nuestra demanda en contra del Estado, el Consejo de Ancianos [ $\left.\mathrm{N}^{\circ} 2\right]$, está de acuerdo con la política empleada por $\mathrm{CONAF}^{33}$.

Los ánimos subieron de tono cuando Ramírez retiró un cerco levantado por los seguidores de Alberto Hotus (en diciembre de 1995). La respuesta de Hotus fue una carta al Director Ejecutivo de CONAF denunciando la arbitrariedad de su subordinado:

Me siento en la obligación de tener que comunicarle la lamentable y desafortunada actuación del Sr. José M. Ramírez, Jefe Provincial de Conaf, en la Isla de Pascua. Se trata de la destrucción, por parte de este Señor, de una cerca que sirve de aprisco para nuestro ganado, perteneciente al Consejo de Ancianos de Rapa Nui, en su ubicación de Hanga Hoonu ${ }^{39}$.

Tres años más tarde, en mayo de 1998, en un memorándum de Ramírez al Gerente de Operaciones de CONAF, le pide que se ponga fin a la cesión de las 900 hectáreas entregadas al Consejo de Ancianos y "solicitar al Sr. Hotus el retiro de los animales y la restitución de las tierras del Parque”, y añadía “...hemos sabido que la propia OCAC estaría solicitando al Sr. Hotus la entrega de los animales a los distintos dueños, en tanto el proyecto del Banco Ganadero resultó en un fracaso"40.

El último argumento de Ramírez, contra el uso del Parque como praderas para el talaje de los animales, era la defensa del patrimonio arqueológico. En carta a la directora del Consejo de Monumentos Nacionales, 
Marta Cruz Coke, sobre el proyecto Banco Ganadero, le sintetiza su postura:

En la práctica, los 72 vacunos originales se convirtieron en más de 200, para un área que no cuenta con pastos suficientes, por lo que deambulan diariamente a lo largo de la costa, y sobre docenas de sitios arqueológicos. El deterioro es visible en algunos sitios con petroglifos ${ }^{41}$.

Es historia sabida que el gran perdedor de esta contienda fue José Miguel Ramírez y con ello parte de la institucionalidad tire. La doble agencia de ganado y ganaderos era más poderosa.

\section{Los yorgo, la ganadería y el Parque}

“...tú puedes ver aquí en la isla a los yorgos que no se hacen ni un problema, tienen sus caballos, si necesitan plata lo arriendan y si quieren viajar se consiguen una mina extranjera por ahî" (Valera 2004:184).

Posiblemente el fenómeno yorgo pueda ayudar a comprender una dimensión más de lo que se juega con la ganadería. Los estudiosos rapanui no están de acuerdo sobre el origen de la palabra yorgo: para unos proviene de la lengua chilena ${ }^{42}$, para otros, como Alfredo Tuki Paté (Comunicación personal, mayo 2018) es una designación local para señalar a una joven "jodido", a "los que hinchan mucho", a los que "molestan", a los "revoltosos" (es decir, los he óro óro). Son los que no se "integran", ni a sus familias ni a las instituciones (desertores del colegio), ni a los trabajos habituales (¿gozan de la libertad del artesano?).

Los yorgo son un grupo de jóvenes rapanui que a mediados de los años 1970, o comienzos de la década del 1980, optaron por un estilo de vida alternativo al "moderno" y "occidental": se fueron a vivir al campo, buscando una subsistencia en la pesca, en la agricultura y en la ganadería. Se le designó, según Viki Haoa y el matrimonio Weber (Comunicación personal, mayo 2018), como here pata (onda). Para Alfredo Tuki son contemporáneos de la fiesta de la Tapati (ahí los yorgo expresaron su rebeldía en los bailes). Andar y moverse a caballo fue posiblemente uno de sus signos más manifiestos. Era una suerte de retorno al mundo previo a la llegada de los europeos y chilenos. De allí también el uso del idioma rapanui. Algunos piensan que está asociado al movimiento hippie de los 60-70, del cual los yorgo serían su expresión local ${ }^{43}$.

Lo interesante del fenómeno yorgo radica no sólo en el uso de las tierras del Parque (para la autoridad chilena una "toma"), sino que además la opción y el estilo vida estaba pensado en oposición al tire. Es lo que se enuncia en un artículo de Emilio Vidanski -"Yorgos, la postal que no se vende de Isla de Pascua" (2015)- relativo al documental de Paco Toledo y José Domingo Ribera titulado "Yorgos". Emilio entrevista a Paco, gracias a lo cual podemos introducirnos a ese mundo. Los yorgo son una "comunidad que se toma el campo y mezcla sus tradiciones orales con la influencia de la cultura moderna, que habla el idioma rapanui mientras el sustento lo consiguen del mar o cultivan sus hortalizas. También crían ganado, caballos y se movilizan por la isla en motocicletas como unos forajidos. Los Yorgos son de temer. Se han distribuidos en distintos clanes repartidos en el territorio y viven en constante conflicto con la autoridad chilena que resguarda el Parque Nacional Rapa Nui, declarado "Patrimonio de la Humanidad" por la UNESCO en 1995 y que les impone un turismo ecologista prohibiéndoles trabajar su propias tierras"44.

Y en cierta concordancia con Petero Edmunds: "La historia cuenta que los yorgo liberaron las decenas de caballos que tenían en sus chacras y los convirtieron en una plaga para romper el cerco turístico que el Estado chileno quería crear en torno a sus lugares sagrados. La acción les dio resultado". Paco Toledo también destaca que los yorgo "ocupan su tierra como una forma de lucha frente a la política del Estado chileno que quiere proteger los lugares turísticos algo que ellos no aceptan ya que prohibirles venerar su arte sagrado es un ataque a su cultura. Son una especie de libertarios, de okupas de su tierra que no quieren inmigración. Su idea es tener su propio gobierno y decidir su forma de vida (...) En cierta medida tienen razón ya que quieren mantener la tradición y mantener su identidad. Eso sí, en la Isla de Pascua no toda la población acepta este modo de vida. Ellos son marginales con mucho poder (Vidanski 2015).

La "comunidad" de los yorgo está también atravesada por el conflicto (y cómo no ? si en el centro está la disputa por la tierra):

Durante la grabación hubo peleas con algunos yorgo quienes querían dinero para autorizarnos a filmarles su cotidianidad. No podíamos pagarles si no se perdía la espontaneidad y la ética del documentalista. La verdad es que se han vuelto muy interesados. Los norteamericanos les enseñaron a pensar en el dinero como objetivo. Pero con mucho trabajo y buen rollo logramos integrarnos en sus familias. Luego el ambiente se relajó.... pero al final la banda de yorgos se dividió por problemas internos de autoridad y hubo violencia entre ellos (Paco Toledo, en Vidanski 2015).

La(auto) comprensión de los yorgo pasa por los caballos, por su libertad de desplazamiento en el "Parque Nacional" (en el lugar de los monumentos, en el lugar de los antepasados), por su falta de control tire y pro-tire, es decir, por laincapacidad de la autoridad de introducir el nomos (lo que es válido para 
los caballos lo es para la tierra). Esta es nuestra hipótesis. Los caballos gozan de una carga simbólica que les permite a los yorgo pensarse, pero también a los ganaderos. Esa conjunción parque-caballo-monumentos es la que también expresó Pedro Olmos en sus grabados realizados en 1975 (en el momento del auge caballar en el Parque).

\section{La agencia $h o ́ i^{45}$}

Retomemos el epígrafe inicial de nuestro trabajo, de Jordi Fuentes. Los hói gozan en el lenguaje rapanui de un estatus que no tienen los otros animales domésticos. Según Fuentes, en la clasificación jerárquica del mundo de los objetos el idioma pascuense tiene una particularidad referida a la existencia de dos series de pronombres posesivos y de dos adjetivos posesivos, siendo los sonidos vocálicos $\boldsymbol{a}$ y $\boldsymbol{o}$ lo que marca la diferencia de las series: "En un grupo incluye todos los nombres de objetos o personas que están subordinadas al que habla (uso de la vocálica $\boldsymbol{a}$ ): alimentos y toda substancia comestible, utensilios domésticos, herramientas, árboles y plantas, animales domésticos (exceptuando el caballo), el marido, la mujer, hijos, nietos y todos los descendientes, personas de rango inferior al que habla, criados, empleados y en caso de militares, la tropa y personas de graduación inferior al que habla, o de quienes se habla. En el otro grupo, incluye todos los nombres de objetos o personas a los que está subordinado el que habla (uso de la vocálica $\boldsymbol{o})$ : prendas de vestir, especialmente la ropa de abrigo, casa y mobiliario, embarcaciones y vehículos, todos los parientes de línea ascendiente (padres, abuelos, bisabuelos, etc.), personas de graduación o cargo superior al que habla o de quien se habla, y entre los animales exclusivamente el caballo" (Fuentes 1960:53-54).

Fuentes se explaya para explicar porqué el caballo está con los objetos o personas que subordinan:

...somos nosotros los subordinados al caballo.

Esto se explica de la siguiente forma: el pascuense considera que el caballo es quién nos lleva, o sea, "tenemos" que subirnos a él. Nos vemos obligados (subordinados) a la voluntad, o la potencia, del caballo para nuestro rápido traslado y para poder recorrer distancias grandes. Sin el caballo seríamos incapaces, impotentes de realizar tales acciones; de ahí, que la potencia, la capacidad, sea del caballo, no nuestra. El caballo es pues, superior a nosotros [...] De esta misma idea de superioridad del caballo, nace el sentimiento pascuense de no matar ningún caballo, ni consumir su carne (Fuentes 1960:55).
¿Qué lugar tienen los hói en los sueños (haúru, o moe varúa)? En 1970 viajó a la isla el destacado psicoanalista Arturo Prat Echaurren (nieto del héroe), alojándose por cuarenta días en la casa de "uno de los patriarcas de la Isla", Leonardo Pakarati. En ese lapso de tiempo pudo comunicarse con la élite rapanui. Interesado por los sueños, no solo por ser la puerta de entrada a todo análisis, sino también porque para los rapanui son "el gran guía de sus vidas" (Prat 1976:544). Entre los sueños recopilados están los del destacado representante rapanui Juan Chávez (Teave), hijo de Daniel Chávez:
Pasé dos semanas sufriendo, y en eso soñé que iba a caballo y veía a mi padre vestido de uniforme de Capitán de Corbeta pero con pantalones cortos. Empezamos a conversar y me dijo que lo perdonase por no haberme anunciado su muerte (Prat 1976:538).

El hijo aparece en el sueño como un subordinado frente al padre poderoso (más aún si anda vestido como capitán de corbeta, aunque con pantalones cortos), no obstante el hijo es también poderoso justamente por andar a caballo. Cada uno está revestido de signos de poder, de objetos en vocálica $a$. Entonces, ¿no serán los hói una suerte de agentes de empoderamiento de los vivos frente al poder de los antepasados? En el Parque Nacional están los antepasados (tupuna) representados por los moai, y ¿no están allí los vivos representados por los hói? marino:

En otro varúa anda Juan y no su padre vestido de

Fui jugador de futbol, mucho tiempo. Y cuando soñaba que está vestido de marino de gala o con fusil o arma de fuego, al levantarme en la mañana sabía que iba a triunfar en el partido. Cuando iba a perder soñaba que andaba desnudo [...]Yo tenía un caballo que fue muchos años campeón de la Isla de Pascua y días antes de la carrera soñaba que la gente lo perseguía a mi caballo por el cerro, por la ladera, por todas partes y el caballo se arrancaba. El sueño era que ganaba el caballo. Ese sueño lo soñé varias veces y siempre ganaba el caballo (Prat 1976:546-547).

¿No gana el hói a los tire por andar suelto, por no poder ser sujetado a un nomos?

Volviendo al tema del daño que hace el ganado al patrimonio arqueológico. ¿Son conscientes los ganaderos de esa realidad? El estudio de la agencia MOBA nos entrega la respuesta: el ganadero percibe de manera desigual su actividad: 
por un lado, la considera beneficiosa para su propia persona, para su familia y para la comunidad y, por otro, no es capaz de percibir el daño que la ganadería genera en el entorno. El $81 \%$ de los ganaderos considera que la actividad ganadera es muy importante para la Isla. El $86 \%$ cree que es muy importante para su familia y el $79 \%$ piensa que es muy importante para él. En cuanto a la repercusión de la ganadería en el patrimonio arqueológico, $33 \%$ cree que la ganadería afecta el patrimonio arqueológico; $31 \%$ cree que lo afecta poco o nada (MOBA 2011:117).

Que el $81 \%$ de los ganaderos consideren que la ganadería es "muy importante" para la Isla sólo se explica por su dimensión simbólica y sus derivados políticos y económicos

\section{El archivo judicial de Pascua}

...el problema principal de la Isla es la cesantía que se refleja especialmente en la gente joven, lo que lamentablemente lleva a un recrudecimiento de hurtos y robos de ganados y otras especies, hecho que no existió cuando se realizaba gran número de obras públicas (12 de diciembre de 1977) ${ }^{46}$.

Si nos valemos ahora del archivo del Juzgado de Isla Pascua, se confirma por esta vía la peculiaridad del caballo: estar al margen del nomos del robo. El archivo judicial de la Isla, entre los años 1966 y 1979, contiene unas 1328 causas, donde es posible dirimir ese nomos. En primer lugar, los robos al Fundo Vaitea de ovejas y vacunos continuó con la vieja tradición del toque (robo) que se le hacía a la CEDIP (entre $3.000 \mathrm{y}$ 5.000 corderos anuales según los administradores). Los cientos de vacunos Hereford del Fundo Vaitea de la década de 1970 no estuvieron entonces al margen de esa práctica:

...El Sr. Gerardo Velasco García-Huidobro, Jefe de Corfo Isla de Pascua, domiciliado en Kainga s/n, expuso: Que al hacer el recuento de los animales del Fundo Vaitea bajo su cargo, entre las fechas 27 de junio y 27 de julio del presente año (1979), pudo constatar la sustracción de la cantidad de 20 vacunos marca Hereford, color colorado y blanco, de propiedad del referido fundo de Vaitea, cuyo delito al parecer se efectuó a través de una alambrada que rompieron los autores materiales del hecho en comento, ubicado en el campo $\mathrm{N}^{\mathrm{o}}$ 9. Hace presente el denunciante que durante la búsqueda efectuada en el Campo Rano Aroi, que deslinda con el Campo $\mathrm{N}^{\circ} 9$, se ubicaron dos cueros de los referidos animales... ${ }^{47}$.

La búsqueda de los 18 restantes animales continuó ya no en los campos sino en Hanga Roa, para lo cual “... se allanó a la totalidad de las Residenciales y Hoteles sin encontrarse observaciones". ¿Es posible que una "pérdida" tan grande de "carne y de huesos" pudiera tener algún grado de complicidad comunitaria?

En segundo lugar, al lado de estos toque están los robos de animales entre los mismos rapanui, los que son cuatro veces superiores a los realizados al Fundo. Este "daño" al capital de las economías familiares afectaba en especial a los vacunos. Ahora bien, la mayor parte de los juicios (unos 42) nos muestra que eran "pérdidas" al interior del sistema parcelario o en las proximidades de la morada de su dueño ${ }^{48}$.

Copiamos algunos párrafos pertinentes de estos procesos:

1967. Denuncia de Leviante Araki: “... en el tiempo que estuve en el continente fueron cuatro los animales que me robaron"49.

1970. Denuncia de Lázaro Hotus: “. . . anoche, ignora la hora, desconocidos le hurtaron una vaquilla color blanco con café, marcada con dos orificios en ambas orejas, la que mantenía pastando en los alrededores del sector de Vai-Arepa"50.

1970. Denuncia de Viviana Pakarati: “...una vaquilla color negro con blanco, marcadas con un corte en el pecho hacia arriba (y el segundo es de color negro), la que mantenía con otros animales en su parcela ubicada en Puna-Pau" (Viviana Pakarati). ${ }^{51}$

1971. Denuncia de Orlando Paoa: “...un ternero color blanco y colorado con marca JP. En la paleta derecha, desde la parcela de Orlando Paoa" ${ }^{52}$.

1979. Denuncia de Juan Haoa Hereveri: “ “. . . anoche, ignora la hora, personas desconocidas, entraron a su parcela, ubicada en el mismo lugar de su domicilio, y le hurtaron desde el interior, una vaca de color blanco de más o menos $350 \mathrm{kgs}$. de peso... en unos roqueríos existentes en el lugar denominado Tahai (...) fueron encontrados, el cuero del vacuno y un guardapolvo de mezclilla color azul (...) es el séptimo que me sustrae desde el mes de septiembre del año pasado",53.

1979. Denuncia de Florencia Atamu Hotus: “...el día viernes 4 del presente a las 16 horas más o menos, llegó hasta su parcela ubicada cerca de los siete "Monos", percatándose que desconocidos le habían hurtado un vacuno de regular estatura y peso, el que avalúa en la suma de \$ 10 mil pesos" $" 54$.

La gran mayoría de estas usurpaciones quedaron sin resolver, sus autores gozaron de la impunidad. De 
allí que la "comunidad" (un sector) se organizara a mediado del año 1972, para ponerle fin:

\section{...Hizo presente Tepano, que él al igual que José PakomioAifiti, enunareunión del pueblopascuense efectuada hace dos meses aproximadamente en la Escuela de la localidad, fueron elegidos como cuidadores de todos los animales de la Isla con el fin de prevenir su robo y cooperarle a los Carabineros en esta clase de delitos ${ }^{55}$.}

Como hemos señalado antes, los caballos quedaron al margen de los robos y cuando hubo una denuncia al tribunal (para el periodo un total de nueve), generalmente fueron tipificados como pérdidas o como una sustracción temporal. Por ejemplo, en septiembre de 1967, Jorge Potahi Pakarati Atamu (50 años, obrero de la Fuerza Aérea), denunció a S.F.T. de haber hurtado, hace tres años atrás, un potrillo marcado en la paleta derecha con un X, y que recién ahora lo encuentra en poder de S.F.T. Ahora bien, cuando se llevó a efecto el comparendo Jorge Potahi expresó que no:

...ratifica el parte policial porque se ha dado cuenta que todo no es más que producto de una lamentable confusión derivada de la existencia de dos caballos provenientes de un mismo dueño que los tenía marcado con la misma letra o sea la $\mathrm{X}$ y que ya el asunto está solucionado (Archivo judicial, Rol nº 102 del 30 de septiembre de 1967).

Otro caso de pérdida:

...el año pasado, después del primer rodeo... se le perdió un caballo colorado, sin marca, de aproximadamente de dos y medios años, de su propiedad, que tenía en el sector de los Siete Moais, buscándolo por la Isla, sin poder ubicarlo y que dicho animal no entró al segundo ni tercer rodeo que se efectuó durante ese año $0^{56}$.

Como se puede apreciar, estas dos denuncias fueron realizadas después de haber hecho el afectado una búsqueda de meses o de años, es como si un caballo no pudiera desaparecer (lo que contrasta con los vacunos y los cerdos, donde la denuncia es inmediata). Los siguientes casos ejemplifican la sustracción temporal. Delfina Tepihe denuncia que mientras compraba en la ECA tres jóvenes continentales, entre 10 y 12 años, le sustrajeron el caballo de su esposo. Otra denuncia: “...ayer, en circunstancia que su hijo R. I., conducía un caballo de su propiedad, por la caleta Hanga Roa, salió a su encuentro, N.T., quien aduciendo que el animal era suyo, se lo quito" ${ }^{\text {57 }}$. Y la última, el turista
Juan Humberto Meuresa puso la denuncia que “...en circunstancia que concurrió al Festival de la Escuela, en un caballar colorado arrendado a Juan Pont Hill, el cual lo dejó amarrado en el cerco frente a ese local y desconocidos se lo robaron, quedando en el lugar la rienda". Posteriormente Juan Pont informaba que el caballo había regresado solo, pero sin la montura ${ }^{58}$.

Lamentablemente no hemos podido acceder al Archivo Judicial para la década de 1980 y siguientes, que nos permitirían observar si esta situación del nomos del "robo" continuó o no. Al parecer sí, porque cuando he preguntado sobre este asunto la respuesta ha sido como de extrañeza frente al "hecho" ya que nadie osaría robar un caballo.

Los caballos no desaparecen, no se roban y, a diferencia de los vacunos, de los cerdos, corderos y aves, no se comen (si bajo la modalidad de charqui). En un juicio a un ladrón de un vacuno, éste trató de engañar al juez y a su secretario, sosteniendo que la carne que había vendido en el mercado no era de vacunos sino de caballo (“...efectivamente estuvo vendiendo carne, en compañía de J.T.P. [...] pero que era de equino, dice de vacuno para venderla más rápido"). El juez Armando Sánchez y su secretario Pedro Riroroko Atán, con larga experiencia en estos asuntos, no le creyeron ${ }^{59}$.

\section{A Modo de Conclusión}

Tenemos todos los elementos para responder a la pregunta ¿por qué los hói pueden circular libremente por la Isla y no los humanos? Los hói adquieren ese valor por su lugar simbólico, ya sea en la lengua (el humano le está subordinado), ya sea en los tapu: no se comen y no se roban. En la disputa soberana por las tierras (con los tire, pero también entre rapanui) los hói han jugado un papel central, al ser vistos como un sustituto de los rapanui (es la tesis que comparten el alcalde Edmunds y los investigadores Gisolf y Ramírez). En otras palabras, han sido también la forma de apropiación del espacio, un espacio que siempre ha estado en disputa.

Por otro lado, como los hói han sido "siempre" una fuente de poder y de distinción, en la muy "jerarquizada" comunidad rapanui, es que se ha prestado para las luchas de poder en el seno de la comunidad. Y en esa lucha de poder se ha generado una "clase": los poderosos ganaderos que son por ello poderosos "terratenientes". Así, detrás del imaginario de que los caballos son un sustituto de la comunidad se encuentran un pequeño pero poderoso grupo: los ganaderos. Así su poder se sustenta en esa dimensión sustitutiva más que en la fuerza (como se desprende del documental "Yorgo" de Toledo y Rivera).

¿Existe un vínculo entre los ganaderos y los empresarios turísticos, sabiendo el daño que producen los caballos semi-salvajes en el patrimonio arqueológico? En marzo de 1975 Godofredo Stutzin, un destacado defensor de los animales, argumentó en la página editorial de El 
Mercurio, a favor de los caballos, insistiendo en su valor turístico:

Junto a los monumentos arqueológicos y las bellezas escénicas los caballos de Rapa Nui son, sin duda, uno de los elementos de atracción turísticas. Observarlos en su vida semi-salvaje, formando parte del paisaje y dándole colorido y movimiento constituye un espectáculo inolvidable. Del mismo modo recorrer la isla a lomo de caballo, única manera de penetrar en sus secretos y en su ambiente, representa una experiencia plena de goce y emoción... Pascua posee en sus caballos un capital turístico del más alto valor. Agréguese a ello la posición especial que el caballo ocupa en el pensamiento tradicional Rapa Nui y que se refleja en el hecho de que el idioma pascuense otorga a este animal el tratamiento propio de los seres superiores" (El Mercurio, domingo 9 de marzo de 1975).

Meses más tarde, la poderosa revista Qué Pasa, que representaba al sector empresarial neoliberal, selló el asunto:

...la existencia de manadas de caballos
semisalvajes puede constituir para los
turistas extranjeros un motivo de tanta
atracción como los moais mismos y que
es de lamentar que esto no incluya en la
propaganda que se reparte en el extranjero.
La trilogía del paisaje espectacular, los
monumentos arqueológicos y los caballos
libres proporcionan un goce estético
incomparable. Los caballos salvajes de
Pascua ya forman parte de la imagen de la
isla y son capaces de atraer una poderosa

corriente de turistas" (Revista Qué Pasa 19/2/1976. El destacado es mío).

Es posible, entonces, que por estas razones, empresarios ganaderos y turísticos corran un tupido velo sobre los efectos negativos de la ganadería caballar.

Los tire siempre se han sorprendido del orgullo "nacional" rapanui y de su capacidad de agencia, la respuesta la han buscado generalmente en su paisaje monumental (los moai), ahora si se mira el complejo mundo de los hói se hará más evidente el sentido y alcance de sus demandas políticas.

Volviendo a la pregunta ¿Por qué se sanciona a una joven continental por subirse a un moai y besarlo y no se sanciona a los dueños de los animales que se suben a un $A h u$ ? Con los antecedentes expuestos ya tenemos una posible respuesta. Y ¿si la que besara fuera una rapanui, habría la comunidad Mau Henua (que administra el Parque) llamado al pueblo rapanui a movilizarse para presionar al tribunal para una dura sanción como lo hizo con la continental? Con lo antecedentes expuestos la respuesta sería NO.

Agradecimientos: Quiero agradecera un grupo de colegas y amigos con los cuales mantenemos una comunicación permanente sobre la investigación en Isla de Pascua y sin los cuales es casi imposible avanzar: Jacinta Arthur, Riet Delsing, Valentina Fajreldin, Vicky Haoa, Alejandra Grifferos, Hans Gundermann, Sonia Montecino, Cristian Moreno Pakarati, Diego Muñoz, Carlos Paoa, Jimena Ramírez, José Miguel Ramírez, Felipe Rivera, Roberto Rojas, Andrea Seelenfreund (por su especial orientación en el trabajo de Jordi Fuentes), Alfredo Tuki Pate, Nancy Weber y Roberto Weber. También agradezco de forma muy especial a los evaluadores por sus numerosas observaciones y sus reveladores comentarios. Y, por ultimo, a Fondecyt, por financiar nuestra investigación en Rapa Nui (proyecto $\mathrm{N}^{\circ} 1170422$ ).

\section{Referencias Citadas}

AMBAR 2001. "Estrategias y acciones para la conservación uso y aprovechamiento sustentable de los recursos patrimoniales de Isla de Pascua. MIDEPLAN, CONADI, CORFO y FDI, ciudad.

Bascopé, J. 2008. Pasajeros del poder propietario. La Sociedad Explotadora de Tierra del Fuego y la biopolítica estanciera (1890-1920). Magallania 36 (2):19-44.

Cristino, C., A. Recasens, P. Vargas, L. González y E. Edwards 1984. Isla de Pascua. Procesos, Alcances y Efectos de la Aculturación. Instituto de Estudios de la Isla de Pascua, Universidad de Chile, Santiago.

Delsing, R. 2017. Articulando Rapa Nui. Políticas Culturales Polinésicas frente al Estado Chileno. LOM, Santiago.
Dirección de Estadísticas y Censos 1965. Isla de Pascua. Rapa Nui. IV Censo Nacional Agropecuario. Dirección de Estadística y Censos, Santiago.

Edwards, R. 1918. La isla de Pascua. Consideraciones Expuestas acerca de ella por Mons. R. Edwards Obispo y Vicario Castrense, que la Visitó en Julio de 1916 y en Junio de 1917. Imprenta San José, Santiago.

Fischer, S. 2005. Island at the end of the world. The turbulent history of Easter Island. Reaktion Books, London.

Figueroa, G. y W. Mulloy 1960. Medidas a fin de salvar el tesoro arqueológico de isla de Pascua. Notas del Centro de Estudios Antropológicos 5 (11).

Foerster, R., C. Moreno y J. Ramírez 2014. Cartografía y Conflicto. Rapa Nui 1888-2014. Rapu Nui Press, Santiago. 
Fuentes, J. 1960. Diccionario y Gramática de la Lengua de la Isla de Pascua. Editorial Andrés Bello, Santiago.

Gisolf, J. 2002. La Ganadería Rapa Nui. El Inicio a la Participación. Tesis para optar al título de Ingeniero Forestal. Van Hall Larenstein, University of Applied Sciences, Velp.

Laferte, E. 1957. Vida de un Comunista. Talleres Gráficos, Santiago.

McCall, G. 1976. Reaction to Disaster: Continuity and Change in Rapanui Social Organization. Tesis para optar al grado de doctor, Australian National University, Canberra.

McCall, G. 1998. Rapanui. Tradición y Sobrevivencia en la Isla de Pascua. Easter Island Foundation, Los Osos, CA.

Melnick, J. y M. Lobell 1952. Informe sobre la Isla de Pascua CORFO, Santiago.

Métraux, A. 1950. La Isla de Pascua. FCE, México DF.

MOBA 2011. Diagnóstico técnico y social de las prácticas ganaderas en Isla de Pascua. Une ethnographie historique de la mobilité dans une société transnationale. CONADI, CONAF, ONF Internacional y Parque Nacional Rapa Nui, Santiago.

Muñoz, D. 2017. Diaspora Rapanui (1871-2015). L'île de Pâques, le Chili Continental et la Polynésie Française. Tesis para optar al grado de doctor, École Des Hautes Études en Sciences Sociales, Paris.

Pakarati, T. y C. Silva 2012. Encuesta de la demanda de carne y derivados en la comunidad Rapa Nui. Taha Tai Consultores, Santiago.

Porteous, D. 1981. The Modernization of Easter Island. Dept. of Geography, University of Victoria, Victoria, BC.

Prat Echaurren, A. 1976. Documento de Isla de Pascua: relatos, sueños y otros fenómenos psíquicos. En Las Islas Oceánicas de Chile, editado por G. Echeverria y P. Arana, T. III, pp. 529-573. Instituto de Estudios Internacionales, Santiago.

Ramírez, J.M. 2004. Manejo del recurso arqueológico en Rapa Nui: teoría y realidad. Chungara Revista de Antropología Chilena 36 (1):489-497.

Ramírez, J.M. y C. Moreno 2018. La relación Estado Chile-Rapanui colonialismo a la chilena. En Tensiones entre Estado y Ciudadanía. Repensando Espacios, Significaciones y Tiempos, editado por E.
Cavieres Fernández y E. Cavieres Figueroa, pp. 71-88. Sello Editorial Puntángeles, Universidad de Playa Ancha, Valparaíso.

Reyes, J.C. y A. Saini 1995. Bancos Ganaderos. Experiencia de Capitalización Campesina en Chile. Fundación Oficina Coordinadora de Asistencia Campesina (OCAC), Santiago.

Valera, R.M. 2004. El Impacto de la Modernidad sobre la Población Juvenil Actual de Isla de Pascua. Tesis para optar al título de sociólogo, Universidad de Chile, Santiago.

Vidanski, E. 2015. Yorgos, la postal que no se vende de Isla de Pascua. http://www.eurolatinpresscultura.com/yorgos-la-postal-que-no-sevende-de-isla-de-pascua/

\section{Otras Fuentes}

Archivo del Juzgado de Isla Pascua José Miguel Ramírez.

Delley, A. 1960. Informe sobre las posibilidades de fomento agrícola y pastoril en la Isla de Pascua, por Arthur H. Delley, Asesor en Administración Ganadera y Producción de Pastos, Misión de Asistencia Técnica, FAO de las Naciones Unidas, en Archivo de la Intendencia de Valparaíso (Caja 1956), Valparaíso.

Ferrari, A. 1939. Informe del viaje ejecutivo a la Isla de Pascua por el médico veterinario sanitario de Valparaíso en diciembre de 1939. Archivo de la Biblioteca William Mulloy, Rapa Nui.

Dirección de Estadísticas y Censos 1965. IV Censo Nacional Agropecuario.

Leighton, E. 2015. Yorgos, la postal que no se vende de Isla de Pascua. Diario El Clarín del 13 de mayo del 2015.

ODEPLAN 1972. Plan de la economía nacional: plan de desarrollo de Isla de Pascua. 1971-1976. ODEPLAN. I (15).

Memoria de Recabarren 1926-1930

Ministerio de Marina

Revista Qué Pasa 1976. Los caballos de Isla de Pascua. Fecha 19 de febrero de 1976

Stutzin, G. 1975. Los caballos: otro atractivo de Pascua. Diario El Mercurio. 9 de marzo.

Toledo, P. y J.D. Rivera 2014. Documental "Yorgos".
${ }^{1}$ Relación de 1866 de los padres misioneros de los Sagrados Corazones en Rapa Nui, en Documentos Sobre Isla de Pascua (1864-1888), Biblioteca Fundamentos de la Construcción de Chile, Vol. 96, p. 53. Santiago, Chile.

${ }^{2}$ Palabras de un rapanui a uno de los relegados comunistas en 1929.

${ }^{3}$ El forraje natural de la Isla esta compuesto por una "gran variedad de pastos [...] siendo el Sporobulus poiretii el más abundante. Estos adquieren mucha dureza con la madurez lo que dificulta la alimentación de los ovinos, causa por la cual periódicamente deben ser quemados para facilitar la salida de brotes tiernos" (Ferrari 1939:3). En 2008 Jean-Yves Meyer "determinó dos factores principales en el deterioro constante de los recursos naturales en Isla de Pascua: (1) el sobrepastoreo de equinos y bovinos en libertad y (2) la quema intencional y el fuego accidental" (MOBA 2011:16).

${ }^{4}$ Desde fines de la década de 1950 se sabía del "daño irreparable" (Figueroa y Mulloy 1960:4).
${ }^{5}$ Una de la mayores claves para la comprensión de la situación "colonial" de Pascua es el sistema parcelario: desde la década de 1920 la Armada comenzó a entregar parcelas de 5 héctareas a los nuevos matrimonios en Hanga Roa. De allí entonces que la demanda por tierras no estuviera en el centro de la revolución de los años 60. El conflicto por las tierras se produjo con la Ley Pascua (1966), cuando el Estado comenzó a instalar sus instituciones civiles en las tierras parcelarias, lo que fue visto por los rapanui como una suerte de expoliación. (véase Foerster-Moreno-Ramírez). Las demandas por recuperar las tierras del Parque Nacional y del Fundo Vaitea (el $80 \%$ de las tierras de la Isla) comenzaron en la década de 1980, gatillada por el D.L. 2.885 de octubre de 1979.

6 "Los 825 caballares del censo en 1965, han aumentado a 5 mil cabezas contabilizadas en octubre de 1971" (ODEPLAN 1971:147)

7 "El Censo agropecuario del Instituto Nacional de Estadística de Chile (INE), del 1996, señala que en aquel entonces en Isla de Pascua existía un total de 3.434 animales, mientras que el censo del año 2007 señala que existía un total de 4.815 animales 
y actualmente se estima que la población es de 6.221 cabezas de ganado en Rapa Nui” (MOBA 2011:110).

${ }^{8}$ En IV Censo Nacional Agropecuario (Dirección de Estadísticas y Censos 1965:20)

9 En "Carpeta 1954. Anexo 40" del archivo de la Biblioteca William Mulloy de Isla de Pascua.

${ }^{10}$ Nos refererimos a los informes del subdelegado marítimo Carlos Recabarren Larrahona (1926-1930), del capitán de navío Edgardo von Schroeders Sarratea (1929-1930), del capitán de fragata Edgardo von Streeter Vicuña (1939), del capitán de fragata Alfonso Zelada Muñoz (1942), del capitán de puerto $1^{\circ}$ clase Ricardo Kompatzki Hornickel (1945-1946) y del jefe militar de Isla de Pascua Luis Aceituno Rojas (1950).

${ }^{11} \mathrm{El}$ promedio recomendado en 1939 era de 4 ovejas por hectárea (Ferrari 1939:3).

${ }^{12}$ En Ministerio de Marina, Vol. 2898, sin foliar.

${ }^{13}$ En Ministerio de Marina, Sección Confidencial, Anexo F., 9 de febrero de 1930.

${ }^{14}$ Ministerio de Marina, Vol. 2757, sin foliar.

${ }^{15}$ Memoria de Recabarren 1926-1930:33.

${ }^{16} \mathrm{El}$ Informe de 20 páginas del capitán de fragata Edgardo Streeter Vicuña, del año 1939, nos fue facilitado por nuestra amiga y colega Alejandra Grifferos.

${ }^{17}$ Ministerio de Marina, Sección Confidencial, Anexo F., 9 de febrero de 1930.

${ }^{18}$ Censo de Recabarren, marzo de 1930.

${ }^{19} \mathrm{El}$ informe de Aurelio Ferrari de 6 páginas "Informe del viaje ejecutivo a la Isla de Pascua por el médico veterinario sanitario de Valparaíso en diciembre de 1939", nos fue facilitado por nuestra colega y amiga Riet Delsing (hay una copia en el Museo de Isla de Pascua). La cita corresponde las páginas 5 y 6 .

${ }^{20}$ Ver informe de Alfonso Zelada (1942).

${ }^{21} \mathrm{El}$ informe de Ricardo Kompatzki se encuentra en el Museo Fonk (carpeta 20: Anexos de 1 al 30 del Informe del Delegado de la Armada, enero 1946). El dato censal rapanui del año 1945 proviene de McCall (1976:321)

${ }^{22} \mathrm{El}$ informe de Luis Aceintuno "Memoria anual de la Jefatura Militar, Isla de Pascua, 1950", nos fue facilitado por el arqueólogo José Miguel Ramirez

23 "Campo Experimental Vaitea. Los servicios están a cargo del agrónomo Sr. Alfonso Carreño desde enero de 1954 y tiene 9 hombres para desarrollar sus actividades en las $71 \frac{1}{2}$ hectáreas que tiene esta campo, cuyo fin principal es la divulgación entre los nativos de los cultivos más apropiados para la Isla" (Informe del Delegado de Gobierno, capitán de navío Alejandro Navarrete, 2/6/1955)

24 "Plan de forestación, Se ha estudiado y ya se comenzó a realizar un plan de 6 años de forestación con 500.000 árboles repartidos en un $80 \%$ de Eucaliptus y 20\% de Pino Insigne" (Informe del Delegado de Gobierno, capitán de navío Alejandro Navarrete, 2/6/1955).

${ }^{25}$ Censo Agropecuario 1965:20.

26 "Memoria actividades departamento Isla de Pascua correspondiente al año 1967', informe de Enrique Rogers (en Archivo Intendencia de Valp. Caja: 1968, № 204-205, F:474 a 508, la cita corresponde a f 480).

27 "Proyecto charqui. En 1971 se acordó reducir la elevada masa caballar de la Isla, se entregó este proyecto a INDAP deshaciendo convenio con particulares que tenían hasta el crédito conseguido. Nunca se ha hecho charqui, sólo se estuvo embarcando carne enfriada de equino durante 1972" (en Carta del director de ODEPLAN al Ministro de Agricultura, Jaime Toha. En Archivo Nacional, Ministerio de Planificación, Vol. 137, sin foliar).

${ }^{28}$ En 1970 su directiva era Presidente: Arsenio Rapu Púa; Vicepresidente: Alfonso Rapu Haoa; Secretario: Germán Hotus Chávez; Director: Nicolás Haoa.

${ }^{29}$ En 1970 su directiva era Presidente: Miguel Teao Riroroko; Vicepresidente: Sebastián Pakarati Icka; Secretario Suplemente:
Roberto Icka Paoa; Tesorero: Lázaro Hotus Icka; Director: Pedro Pate Pakomio.

${ }^{30}$ Oficio ordinario $\mathrm{N}^{\circ} 110$ del 20 de enero de 1977, del Ministro Director de ODEPLAN y Presidente de la CONADIP al Asesor Cultural de la Junta de Gobierno, en Archivo Nacional, Ministerio de Planificación, Vol. 205.

${ }^{31}$ MOBA 2011:16. Para el año 2001: “...teniendo en cuenta la metodología empleada y la percepción obtenida en los dos viajes a la Isla de Pascua de esta consultora, la carga animal actual está muy próxima a la calculada sobre la base de los rendimientos medidos en terreno" (AMBAR 2001:4-30).

${ }^{32}$ Mario, casado con Mariana Paté Niare

${ }^{33}$ En Archivo particular de Alberto Hotus (Rapa Nui).

${ }^{34}$ Para Bancos Ganaderos en Chile ver la obra de Reyes y Saini (1995).

${ }^{35}$ En Archivo José Miguel Ramírez.

${ }^{36}$ En Archivo José Miguel Ramírez.

${ }^{37}$ En Archivo José Miguel Ramírez.

${ }^{38}$ En Archivo José Miguel Ramírez.

${ }^{39}$ En Archivo José Miguel Ramírez.

${ }^{40}$ En Archivo José Miguel Ramírez.

${ }^{41}$ En Archivo José Miguel Ramírez, carta fechada 23 de septiembre de 1998.

42 "Quant à l'origine du mot nous avons recueilli sur place la version suivante. On raconte avec humour que l'origine serait une mauvaise prononciation du mot corvo, un couteau utilisé au Chili et en Argentine par les éleveurs de bétail. Un jour un éleveur de chevaux a été vu dans le village arborant de façon ostentatoire un corvo attaché à sa ceinture. Dans la rue, une personne, sous les effets de l'alcool l'insulta lui disant: " pour qui tu te prends avec ce iorgo! » Les gens qui observaient la scène ont ri du fait de la faute de prononciation, et le mot a intégré le vocabulaire insulaire pour se référer à un style vestimentaire, un type d'activitée économique et dans un sens plus ample, un mode de vie" (Muñoz 2017:267-268).

43 "Expulsarán de Pascua a todos los hippies. Los pocos hippies también han invadido la Isla de Pascua alarmando a los dos mil habitantes que amantes de sus tradiciones han iniciado una verdadera batalla para expulsarlos de su terruño", $L a$ Tercera 5/7/1973. Uno de los más famoso hippies en la Isla fue el hijo del Secretario de Defensa de los Estados Unidos, Robert McNamara.

${ }^{44} \mathrm{En}$ http://www.eurolatinpresscultura.com/yorgos-la-postal-queno-se-vende-de-isla-de-pascua/.

${ }^{45}$ Según Fuentes la expresión hói para designar a los caballos proviene de la palabra inglesa horse (1960:209).

46 "Informe del Gobernador a la Intendencia sobre obras de adelanto en la Provincia de Isla de Pascua, 12 de diciembre de 1997", en Archivo de la Intendencia, Caja 1973 a 1978, N ${ }^{\circ}$ 36 a 38 .

${ }^{47}$ Archivo Judicial, Rol No 1235, del 17 de agosto de 1979.

${ }^{48}$ En demanda de María Dolores Pakomio contra Manuel Tepano, Juan Chávez, Juan Nahoe, Orlando Paoa, Juan Pakomio Domingo Pakarati, Farenet Pakomio, Jorge Pakomio, Elías Rapu, Ruperto Tepano y Luis Laharoa, porque sus vacunos entraron a su parcela ubicada en Vana-Vai-Tokerau, "comiéndose y destruyendo la plantación que mantenía allî”" (Archivo Judicial Rol No 133, del 24 noviembre de 1969).

${ }^{49}$ Archivo Judicial, Rol No 44, del 10 de enero de 1967.

${ }^{50}$ Archivo Judicial, Rol No 170 , del 30 de junio de 1970.

${ }^{51}$ Archivo Judicial, Rol No 187, del 10 de septiembre de 1970.

${ }^{52}$ Archivo Judicial, Rol N ${ }^{\circ} 210$, del 20 de enero de 1971

${ }^{53}$ Archivo Judicial, Rol No 1137, del 2 de abril de 1979.

${ }^{54}$ Archivo Judicial, Rol No 1161, del 7 de mayo de 1979.

${ }^{55}$ Archivo Judicial, Rol No 301, del 12 de julio de 1972.

${ }^{56}$ Archivo Judicial, Rol No 439, del 8 de abril de 1974.

${ }^{57}$ Archivo Judicial, Rol No 809, del 15 de marzo de 1977.

${ }^{58}$ Archivo Judicial, Rol No 961, del 27 de febrero de 1978.

${ }^{59}$ La causa corresponde al Rol N 1247 , del 31 de agosto de 1979. 
